\title{
A IMPORTÂNCIA DO USUÁRIO NA METODOLOGIA DE PROJETO EM DESIGN
}

\author{
Letícia Vasconcelos Morais Garcez, mestranda \\ PPGAU - Universidade Federal de Uberlândia \\ leticiavmgarcez@hotmail.com \\ Patrícia Pimenta Azevedo Ribeiro, Drạ \\ PPGAU - Universidade Federal de Uberlândia \\ pparibeiro2003@yahoo.com.br \\ Juliano Aparecido Pereira, Dr \\ PPGAU - Universidade Federal de Uberlândia \\ pjuliano_ufu@yahoo.com.br
}

Resumo: A existência de usuários é sempre considerada, entre as metodologias de projeto em design, para a caracterização do problema a ser resolvido. Essas metodologias, que servem a uma prática profissional, são utilizadas também no ensino de design em situações simuladas, onde geralmente se cria um usuário fictício, um personagem. Este artigo busca refletir sobre a importância de adoção de um usuário real no exercício de projeto em sala de aula. A discussão do artigo contempla uma reflexão teórica baseada em estudos sobre metodologia de projeto e realiza também a análise de uma experiência prática de Ateliê, em que foi adotado um usuário real. Os autores aqui estudados sobre processo de projeto abordam duas metodologias. Uma que pode ser definida como linear, onde se deve cumprir uma sequencia de etapas delineadas entre a caracterização do problema e a solução de design. E a segunda, cuja principal característica é um processo cíclico, em que os resultados de uma etapa mais avançada voltam a alimentar as etapas anteriores, de onde o processo se reinicia. Enquanto as primeiras metodologias consideram o usuário apenas nas etapas de coleta de dados, a segunda considera, ao longo do processo, que o usuário também forneça feedbacks sobre as soluções de projetos que estão sendo construídas. A experiência de Ateliê que é avaliada neste artigo, trata de um exercício em que foi desenvolvido um conjunto de mobiliário para uma praça, denominada Manaain, na cidade de Uberlândia. A área institucional destinada a essa praça é parte de um conjunto habitacional construído pelo Programa Minha Casa Minha Vida, do Governo Federal. Como resultados da reflexão conclui-se que as metodologias estudadas são pertinentes ao processo de projeto, mas, em relação ao ensino, a segunda permite uma dinâmica mais próxima da prática real, pela interação que propõe com o usuário. A experiência de Ateliê que foi analisada reforça essa importância da aproximação com o usuário real, mesmo que o projeto seja apenas um exercício. 
Palavras-chave: Usuário e ensino de projeto, Metodologia de Projeto em Design, Processo de Projeto, Teoria e Prática do Projeto.

\begin{abstract}
The existence of users is always considered, amongst the methodologies of design, in the characterization of the problem to be solved. These methodologies, which work as professional practice, are also used in the teaching of design in simulated situations, where a fictional user, a character, is usually created. This article seeks to reflect on the importance of using a real user in the exercise of design in the classroom. The discussion of the article proposes a theoretical reflection based upon studies about methodology of design, and also performs an analysis of a practical experience of Studio, in which a real user was assigned. The authors here studied, regarding the process of design, tackle two methodologies. The first one can be defined as linear, where a sequence of stages traced between the characterization of the problem and the solution of design must be accomplished. The second has a cyclical process as a main characteristic, in which the results of a more advance stage give feedback to the previous ones, from where the process restarts. While the first methodologies consider the user only in the stages of data collection, the second considers, throughout the process, that the user should also supply feedback about the solutions of designs that are being built. The experience on the Studio, which is evaluated in this article, is about an exercise in which was developed a set of furniture for a square named Manaain, in the city Uberlândia. The institutional area assigned to this square is part of a housing development built by the program Minha Casa, Minha Vida (roughly translated as My Home, My Life) from the Federal Government. As results of the reflection, one can conclude that the methodologies studied are pertinent to the process of design, but, regarding teaching, the second one allows a dynamic that is closer to the real practice, because of the interaction that it proposes with the user. The experience of Studio that was analyzed reinforces this importance of approximation to the real user, even if the project was just an exercise.
\end{abstract}

Keywords: User and design education, Design Methodology, Design Process, Theory and Design Practice.

\title{
1 INTRODUÇÃO
}

As escolas de Design, segundo Munari (1998), são designadas a preparar indivíduos capazes de enfrentar o mundo de acordo com as técnicas existentes e suas diretrizes curriculares devem levar em conta os problemas atuais. Desta forma, nas escolas, as técnicas existentes necessitam serem organizadas de maneira a possibilitarem as respostas projetuais para as soluções de problemas. $E$ o ensino precisa também envolver práticas reflexivas, fazendo assim sinapses com o ofício. A adoção da realidade, e não a sua simulação, pode ser um recurso que favoreça esse processo reflexivo, por partir de fatos e dados reais.

Donald Schön em 2000, ao constatava que as escolas, naquele momento, apresentavam ensinos voltados para conhecimentos científicos e apenas $1 / 3$ voltado 
para a prática. Bonsiepe já em 1983, afirmava a necessidade de uma educação que valorizasse o aperfeiçoamento das capacidades concretas de projeto, priorizando os instrumentos de reflexão na ação necessários ao processo projetual, permitindo melhor assimilação do aprendizado e incentivando a capacidade produtiva (BONSIEPE, 1983).

O ensino contemporâneo de Design propõe uma abordagem prática reflexiva através de disciplinas orientadas para o ofício. Essas disciplinas são denominadas de Ateliê ${ }^{1}$ ou disciplinas de Projeto. Nessas disciplinas a experimentação da metodologia de projeto acontece através de um problema simulado para a tarefa do aprender, possibilitando aos alunos construírem e experimentarem um mapa do caminho que devem traçar para solucionarem o problema simulado (SCHÖN, 2000).

A curiosidade e a investigação são atividades naturais do ser humano. Porém a pesquisa realizada para solucionar problemas de design necessita de uma ordenação mais rigorosa em termos de métodos e processos. Esse emprego de métodos e processos para o desenvolvimento de soluções aproxima o contexto teórico e prático que acontece no momento de criação de um projeto.

No desenvolvimento de projeto existem vários procedimentos, dos quais a concepção é um deles, contribuindo para se alcançar objetivos / produtos, estruturando assim metodologias. Estas se dedicam aos estudos de investigação, análise e descrição do problema e criação e verificação da solução. A metodologia é o norteador de projetos através do cumprimento de um roteiro que fundamenta ou aprofunda a própria base de uma ciência e de seus objetos de estudo (COELHO, 2006).

A pesquisa no exercício do projeto deve caracterizar o problema a ser resolvido, o que auxiliará na busca de conceitos, princípios e ideias, reunindo informações para a descoberta de diretrizes a serem consideradas nas soluções de projeto. Trata-se de uma declaração de características que o ambiente construído ou o objeto deveria incorporar e conter, como ligação entre as informações reunidas e a solução do projeto (SNYDER e CATANESE, 1984).

A seguir é apresentada uma discussão sobre algumas metodologias de projeto relacionando-as ao ensino de design e a consideração da presença do usuário ao longo do processo.

\section{ENSINO E PRÁTICA: APROXIMAÇÃO ATRAVÉS DA METODOLOGIA DE PROJETO DE DESIGN CENTRADO NO USUÁRIO}

Conforme Argan (2001) arquitetos e designers entendem a metodologia como "ordem do fazer", como processo. A processualidade metódica se dá no fazer com método, que é a ação de projetar, onde se define o momento ideativo e momento executivo, respectivamente como momento espiritual e momento prático. A técnica, que é apresentada na metodologia, traz a síntese desses dois momentos.

O termo método possui o sentido de "meio para", ou seja, a técnica empregada para solucionar problema de determinada etapa do desenvolvimento do projeto. 0 conjunto ordenado das etapas dos "meios para" compõem o processo de projeto,

\footnotetext{
${ }^{1}$ Ateliê, modelo educacional para a reflexão na ação, pratica do exercício do projeto, guiada por um orientador (SCHÖN, 2000). O Ateliê tem como objetivo possibilitar ao aluno o domínio da expressão gráfica, desenvolver a sensibilidade e a capacidade criadora e relacionar o ensino da arquitetura com a realidade profissional (PEREIRA, 2009, P.59).
} 
como "ordem do fazer". Os estudos dos "meios para" e da "ordem do fazer", organizados de forma cientifica formaliza a metodologia de projeto.

Conforme Guimarães (1997) desde os mais pré-históricos artefatos, o homem emprega métodos para a sua fabricação, respeitando uma sequência de ações, as propriedades do material e os recursos disponíveis, teoriza procedimentos ou métodos formando um conjunto de ações para a execução do artefato. Métodos e processos, são ferramentas que devem pertencer ao universo do design para que as soluções propostas sejam efetivas. Existe um grande número de bibliografias que abordam esse conjunto de etapas e técnicas. Entre estas metodologias existem aquelas com um processo mais linear em que a presença do usuário se faz mais na parte inicial, e as metodologias de projeto em que o usuário atua de forma mais participativa, colaborando com as etapas do projeto, realimentando o processo de projeto que é cíclico.

Para exemplificar, foram selecionadas algumas metodologias que a seguir serão discutidas. Entre as designadas lineares, serão apresentadas as desenvolvidas por Bruno Munari, Mike Baxter e Bernd Löbach. Para a compreensão das metodologias cíclicas serão apresentadas a proposta de Snyder e Catanese e um estudo da proposta denominada XDM (eXtensible Design Methods) estruturada por um grupo de professores e alunos da UFPE - Universidade Federal de Pernambuco.

\subsection{Metodologias de Projeto}

A partir da década de 1960, surge uma primeira geração de processos de design, estruturada de forma linear. Os produtos eram desenvolvidos, lançados no mercado para então se verificar sua aceitação. O caminho de concepção era da "fábrica" para o usuário (NEVES, et al, 2008). As metodologias de projeto com caráter mais linear foram apresentadas inicialmente por Munari, em 1981, por Baxter em 1998 e por Löbach em $1976^{2}$ (Figura 1). Apesar de algumas particularidades, estas se estruturam a partir de quatro etapas fundamentais:

- Levantamento de dados

- Geração de propostas

- $\quad$ Avaliação das propostas

- $\quad$ Realização e implementação da ideia;

\footnotetext{
2 Bruno Munari publica em 1981 a 1a edição do livro "Da cosa nasce cosa", pela editora Laterza; Mike Baxter em 1998 publica a 1a edição do livro "PRODUCT DESIGN - A practical guide to systematic methods ofnew product development", pela editora CHAPMAN \& HALL, Bernd Löbach publica em 1976 a 1a edição do livro "INDUSTRIAL DESIGN: Grundlagen der Industrieproduktgestaltung" pela editora $K$. Thiemig.
} 


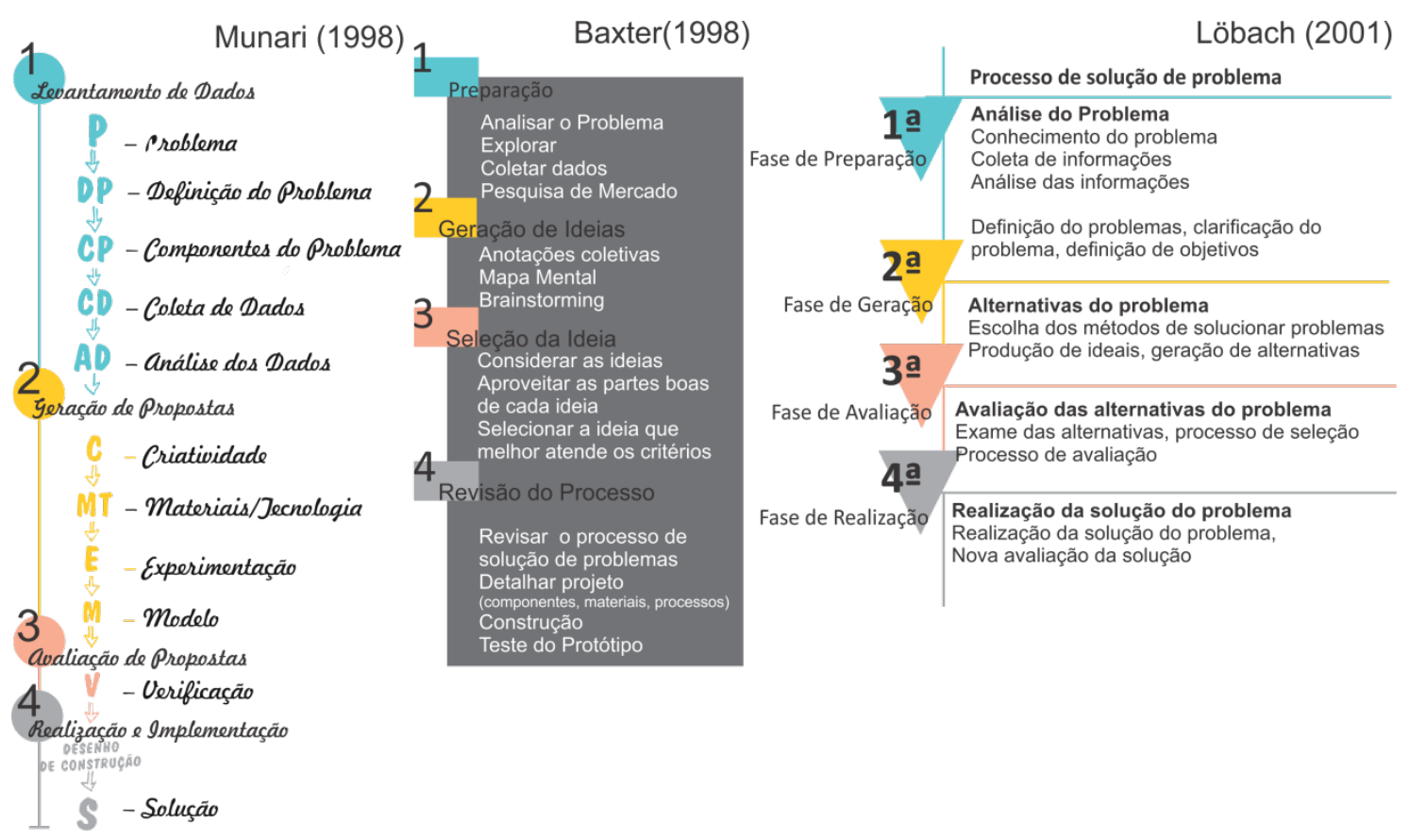

Figura 1 - Metodologias de Projeto de Design Lineares

Fonte: Adaptada por Autora de Munari, (1998); Baxter, (1998); Löbach, (2001).

De acordo com a figura acima, nota-se que o usuário não interfere em todas as etapas de projeto, no sentido de contribuir para os avanços ou realimentação de cada etapa.

Ao realizar um projeto, este se destina a um usuário, ou a um conjunto de usuários, que apresentam as necessidades que o projeto deve viabilizar. Por sua vez as metodologias que consideram os usuários participativos em todas as etapas de idealização do projeto, possibilitam ao usuário contribuir com todo o percurso e a construção do resultado final do projeto.

Em arquitetura uma casa é mais que um problema de construção, e em design um produto é mais que apenas um problema de produção. Se constrói e se produz para um usuário, e é este com suas complexas necessidades, submetidas a uma dinâmica cultural, que figura no centro das preocupações do arquiteto e do designer. Estes formulam o programa do projeto, desde as necessidades que o produto deve atender, à seleção dos materiais mais adequados, assim como desenham os detalhes para a execução do projeto, ou seja, utilizam uma série de processos (BONSIEPE, 1983).

De acordo com Argan (2001) quando se quer que um objeto cumpra uma função, esta deve ser pensada na elaboração do projeto. O projeto deve ser viável prevendo meios e fases de execução, mas sem esquecer de considerar para quem se projeta, para qual sociedade. Desta forma, no processo de projeto, a compreensão do cliente e do seu papel no processo é o primeiro passo, como objetivo, para solução do problema arquitetônico e ou de design, pois é o usuário que contribui para estabelecer as metas gerais do programa de necessidades ou briefing ${ }^{3}$.

\footnotetext{
3 "O briefing no design é visto como um documento completo das necessidades e restrições do projeto, com informações sobre o produto, mercado (público-alvo, concorrência), diferenciais a serem explorados como: custo, tecnologia, apelo estético, entre outros. Este documento apresenta-se como um guia estratégico para o designer e/ou para a equipe de projeto." (PAZMINO, 2015, p. 22).
} 
Entre as metodologias consideradas cíclicas, o processo de projeto proposto por Snyder e Catanese, em 19844, (Figura 2), para projeto de arquitetura, apresenta cinco passos para resolução de problemas. O ponto de partida, de iniciação, consiste no reconhecimento e definição do problema a ser resolvido. O segundo passo é o de preparação, que refere-se à coleta e análise de informações sobre o problema, conhecido por muitos como briefing. O terceiro passo trata da geração de ideias e de propostas de construção. O quarto passo é o de avaliação, que ocorre em diversas escalas e inclui uma grande variedade de participantes, que avaliam e comparam as soluções de projetos propostos com as metas e critérios estabelecidos na fase de preparação. A quinta é a fase da ação, etapa que inclui as atividades associadas a implementação de um projeto. Dentro desta metodologia de cinco passos não há uma rigidez linear, pois trata-se de um processo interativo com o usuário, em que novas informações obtidas fazem com que o projetista reconsidere as já existentes, o feedback do usuário contribui para a natureza cíclica do processo. Assim o processo se torna de interação e iteração, se realimenta e depende de aprovação, em cada estágio, pelo cliente, o que caracteriza esse processo como cíclico, avançando apenas quando há concordância entre todos (SNYDER, CATANESE, 1984).

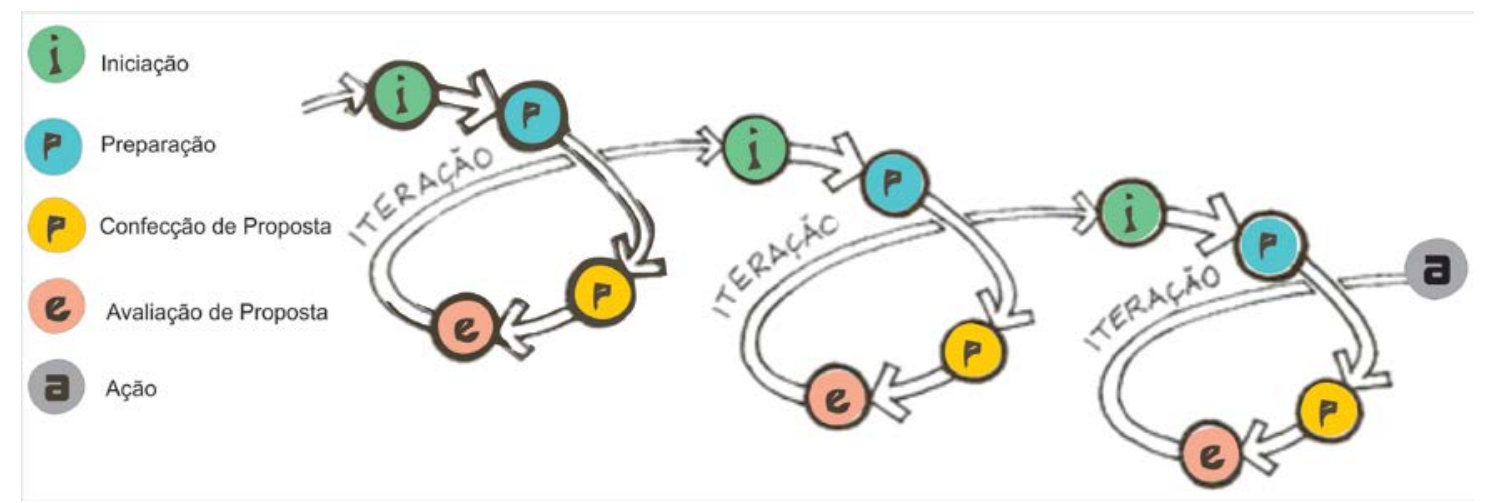

Figura 2 - Metodologia de Projeto em Arquitetura Centrada no Usuário Fonte: Adaptado por Autora de Snyder e Catanese, (1984).

De forma semelhante no âmbito do design, através das pesquisas em metodologia, surgem processos em que as fases de projeto não ocorrem mais de forma linear, e sim de forma cíclica, onde uma fase realimenta a outra e o designer pode voltar à fase anterior a qualquer ponto do processo. Esses são os métodos centrados no usuário, argumentativos, com soluções reguladas pela satisfação, tendo os usuários como parceiros na definição da solução (NEVES, et al, 2008).

A XDM - eXtensible Design Methods - uma metodologia de projeto desenvolvida por alunos e professores da UFPE (Figura 3), se apropria de métodos tradicionais de design modificando-os à medida que incorpora hábitos da contemporaneidade em sua execução. É um processo de design mais ágil e globalmente interligado, pois se utiliza da cibernética, ou pode-se dizer da cibercultura, que é uma relação de trocas entre a sociedade, a cultura intermediada pelas novas tecnologias de base micro-eletrônicas surgidas na década de 1970, graças à convergência das telecomunicações com a informática (NEVES, et al, 2008). A metodologia denominada XDM apresenta cinco

\footnotetext{
4 James C. Snyder e Antony J. Catanese publica em 1979 a 1a edição do livro "Introdution to Architecture" pela editora McGraw-Hill,Inc.
} 
etapas como base do processo. A primeira é a exploração do problema, em que ocorre a construção de um cenário amplo sobre o artefato que será projetado. A segunda etapa é a de geração de alternativas, que consiste na ampliação das possibilidades e soluções para o artefato projetado. A seleção de alternativas é a terceira etapa, em que são reduzidas o número de alternativas geradas, e é selecionada a que melhor atende às expectativas. A quarta etapa é a de avaliação de alternativas e seleção de uma delas de modo que, esta alcance um nível satisfatório, apresentando um conjunto de prioridades adequadas ao artefato projetado. Por fim a quinta etapa, a da descrição da solução final do projeto, é apresentada para ser implementada em documentos sucintos e claros (NEVES et al., 2008). O diferencial do XDM é que cada etapa do processo de projeto é postada no "weblogs", espécie de diários publicados na internet que o designer convida um conjunto de profissionais e potenciais usuários para participarem do processo, contribuindo de forma direta com a concepção da solução, comentando os posts inseridos ao longo do processo. (NEVES et al., 2008). É este procedimento que torna cíclica essa metodologia de projeto.

\section{eXtensible Design Methods}

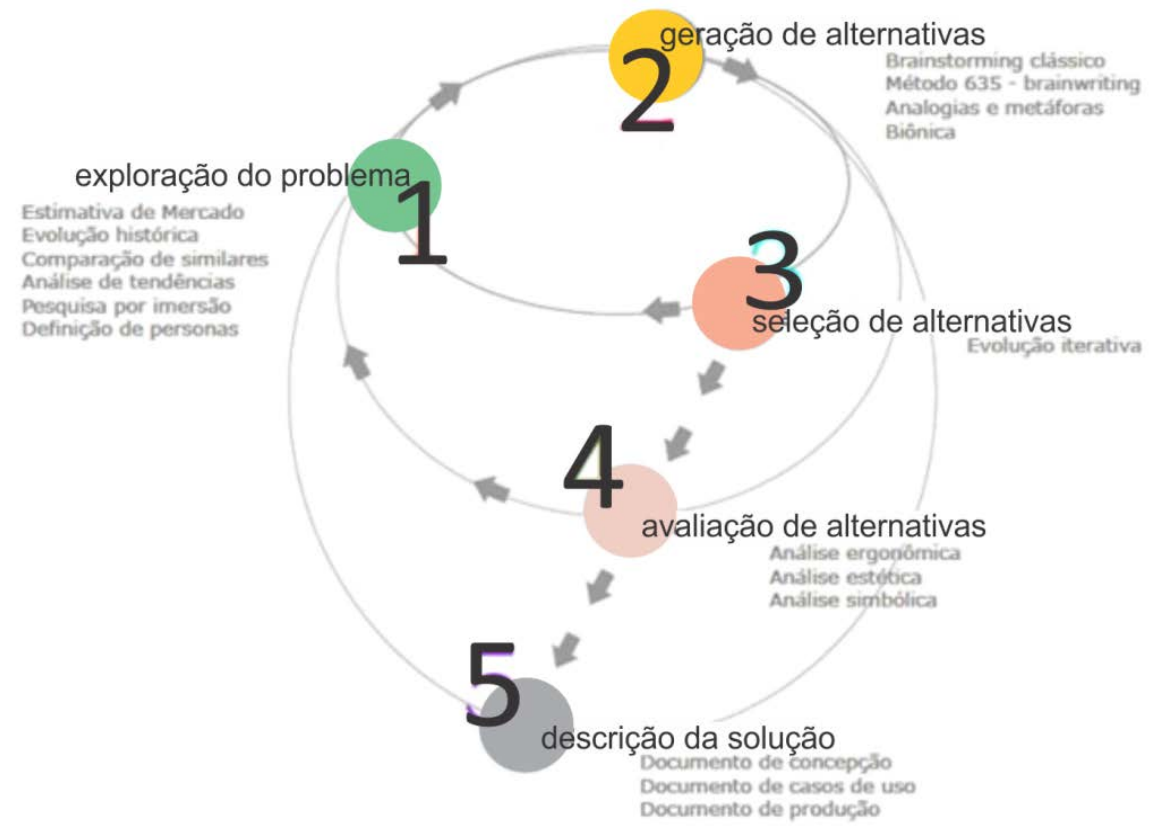

Figura 3 - Metodologia de Projeto em Design Centrado do Usuário Fonte: Adaptado por Autora de NEVES, et al, (2008).

\subsection{O USUÁRIO E O PROCESSO DE PROJETO NO ENSINO}

Pode-se evidenciar que diante da literatura de metodologia de projetos quando esta é centrada no usuário, existe uma relação mais estreita entre projetistas e usuário, modificando assim a linearidade do processo de projeto que passa a ser realimentado e mais interativo. Desta forma nota-se a importância de se incluir a presença do usuário nos exercícios de projetos acadêmicos, para que os alunos passem a desenvolver projetos a partir de contextos mais reais e que a aprovação do mesmo dependa da relação de outra figura, antes apenas representada pelos professores. 0 usuário através desta relação contribui com o eixo prático do ensino, em que os 
professores orientam os alunos a desenvolver projetos a partir de um briefing real e não de um briefing previamente idealizado pelo mesmo e entregue aos alunos.

Partindo deste entendimento, a disciplina Design do Mobiliário 2, do curso de Design da FAUeD/UFU - Faculdade de Arquitetura e Urbanismo e Design da Universidade Federal de Uberlândia, ministrada pelos docentes Juliano Aparecido Pereira e Sandra Resende, durante parte do segundo semestre de 2015, propuseram um exercício de projeto de mobiliário para a praça do Jardim Manaain. O projeto da Praça foi idealizado pela estudante Melina Oliveira em seu Trabalho Final de Graduação, TFG, que tinha como objetivo o "desenho participativo" da praça. Entre alguns elementos de projeto que o TFG contemplaria haveriam as peças de mobiliário, e diante disto foi proposto um trabalho interdisciplinar entre estudantes do curso de Design da FAUeD - UFU e o TFG em Arquitetura da aluna em questão.

Através deste exercício proposto os discentes puderam refletir durante a ação de projetar a partir de uma aplicação prática e contato direto com os usuários dos produtos/ mobiliário que viriam a atender a reais necessidades de uma comunidade. Esta condição foi modificadora do próprio processo de projeto, pois os moradores apresentaram feedbacks que interferiram na linearidade do processo. Os estudantes antes acostumados a receberem um briefing já pré-definido pelos professores, neste projeto, tiveram que levantar informações através de uma primeira reunião com os moradores do bairro, para conhecer o que estes tinham como desejo de mobiliário para a praça.

Para a primeira reunião para formatação do briefing (Figura 4) os alunos elencaram algumas perguntas: Que mobiliário é desejado? Quais as características de cada um deles? Para direcionar o diálogo com os moradores, colocaram na parede do salão de convívio de uma igreja do bairro, um conjunto de imagens de praças e de seus mobiliários. Os moradores foram convidados a opinarem sobre as características dos objetos presentes nestas imagens e ao final do diálogo estabeleceram-se quais seriam os equipamentos a serem projetados. Definiu-se por bancos com e sem encosto, mesas para jogos, luminárias, lixeira, totem com o nome da praça e um parquinho infantil.
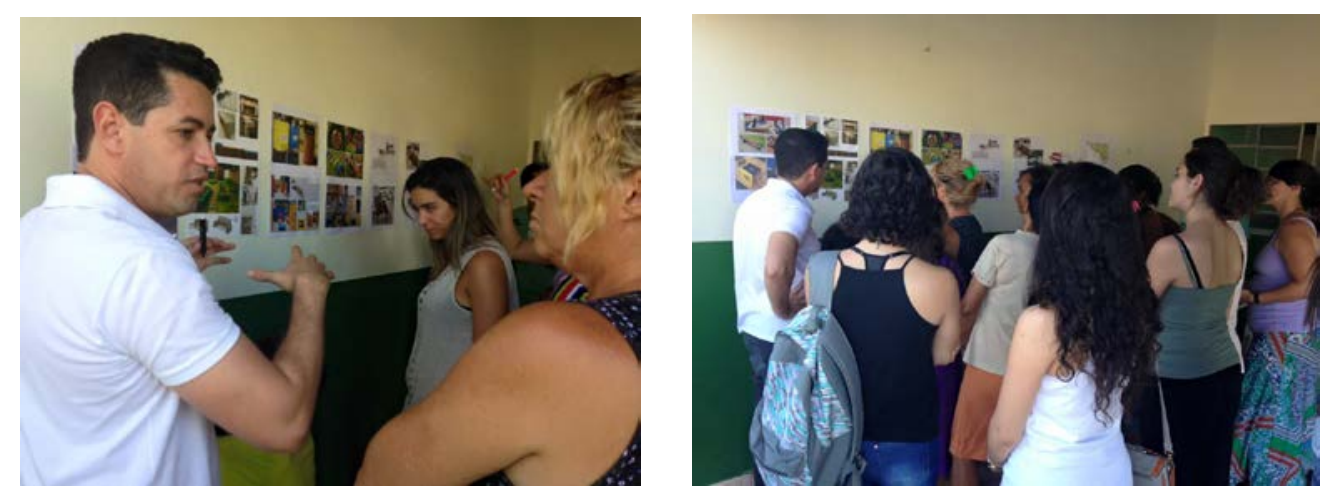

Figura 4 - Definição do Briefing

Fonte: Foto da primeira reunião dos alunos do curso de Design com a comunidade para definição do briefing para o projeto de mobiliário da Praça Manaain.

A partir deste diálogo, os estudantes compreenderam as necessidades da comunidade, considerando aspectos funcionais, ergonômicos, estéticos e simbólicos. Um ponto interessante de ressaltar sobre esta atividade, está relacionado aos aspectos 
ergonômicos e funcionais que os estudantes tiveram que considerar durante a atividade de projeto. Ao se depararem com o mobiliário exposto na parede, os moradores comentaram sobre a considerável quantidade de pessoas idosas ou portadoras de algum tipo de necessidade especial residentes no bairro. Esta característica se justifica em função do bairro Manaain ter sido construído através do programa de habitação popular do Governo Federal, Programa Minha Casa Minha Vida, o qual prevê uma porcentagem das unidades habitacionais para o atendimento a esta parcela populacional. Os materiais e as tecnologias adotadas nos projetos também passaram a ser consideradas a partir desta primeira reunião. Diante da possibilidade da praça ser realizada em processo de mutirão pelos próprios usuários com apoio da prefeitura municipal de Uberlândia, foram estabelecidos materiais cuja tecnologia construtiva fosse de fácil acesso aos moradores: alvenaria de tijolos, concreto, madeira, aço (vergalhão e chapas perfuradas), por exemplo.

Retornando ao Ateliê, os alunos foram divididos em grupos em que cada equipe ficou responsável por um determinado projeto de mobiliário de acordo com os requisitos estabelecidos no briefing. Uma das preocupações foi de que toda a linha de mobiliário tivesse uma mesma linguagem, a fim de instituírem um conjunto de produtos com características semelhantes, conferindo uma unidade à praça. Para se alcançar esse objetivo, ao final das reuniões de Ateliê, os estudantes com a orientação dos professores discutiam os resultados intermediários alcançados e quais diálogos seriam possíveis entre as peças, estabelecendo-se assim uma dinâmica mais colaborativa dentro do próprio Ateliê, semelhante ao que se ocorre na prática de um escritório de projeto. Juntamente com o projeto de mobiliário os estudantes desenvolveram o logo para o nome escolhido pelos moradores para a praça. A praça, em votação dos moradores, levou o mesmo nome do Bairro, isto é, Praça Manaain.

$\mathrm{Na}$ segunda reunião dos estudantes do curso de Design com os moradores, foram apresentadas as propostas de mobiliário desenvolvidas. $O$ encontro aconteceu no próprio terreno destinado a praça e o material utilizado para apresentação foi composto por maquetes físicas e pranchas impressas com perspectivas eletrônicas renderizadas (Figura 5). 

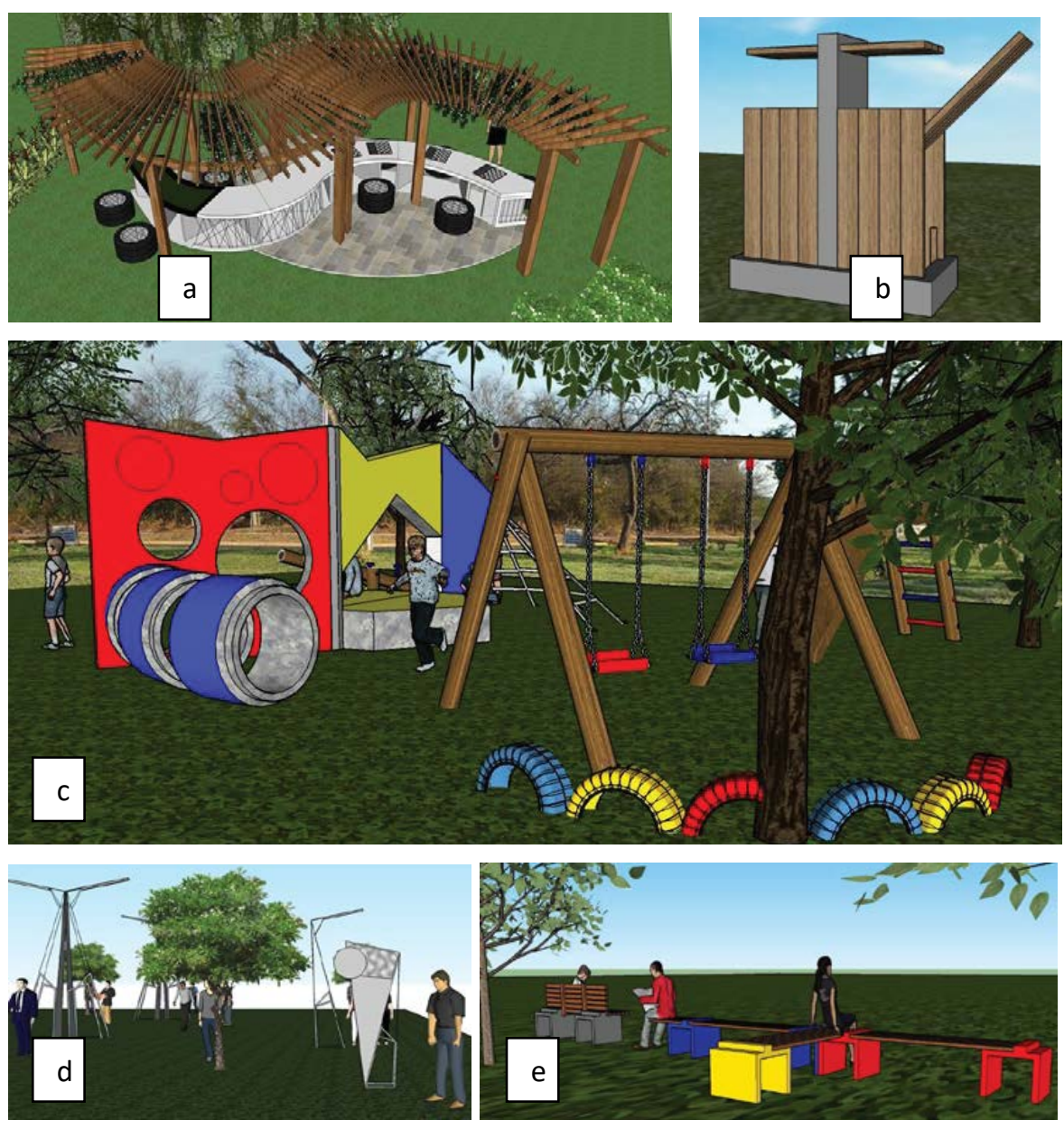

Figura 5 - Perspectivas Eletrônicas - Propostas de Mobiliários

Legenda: Perspectivas eletrônicas apresentadas pelos alunos com propostas de mobiliários para a Praça Manaain (a- Ilha de Jogos / b- lixeira / c- Parquinho / d - Poste de lluminação e Totem / e - Bancos).

Fonte: Caderno de projeto para mobiliário da Praça Jardim Manaain (2015)

Apesar do improviso do espaço expositivo para a apresentação dos projetos, (Figura 6) esta se deu de forma satisfatória e bastante interativa com todos os moradores, adultos e crianças, principalmente através das maquetes físicas. Após esta apresentação realizou-se uma avaliação geral pelos professores diante do cumprimento das expectativas dos moradores do bairro, futuros usuários da praça, em relação aos projetos, o que possibilitou a integralização de um Caderno de Projeto que possui a documentação das perspectivas eletrônicas e os devidos desenhos técnicos e detalhamentos necessários à execução do mobiliário.

Este processo representa um momento oportuno para reflexões de projeto para além dos limites do Ateliê, possibilitando o contato com uma realidade concreta e implicando novos desafios, semelhantes aos que estes alunos vivenciarão quando estiverem atuando no mercado de trabalho, através de negociações de projeto diretamente com o "cliente / usuário". 

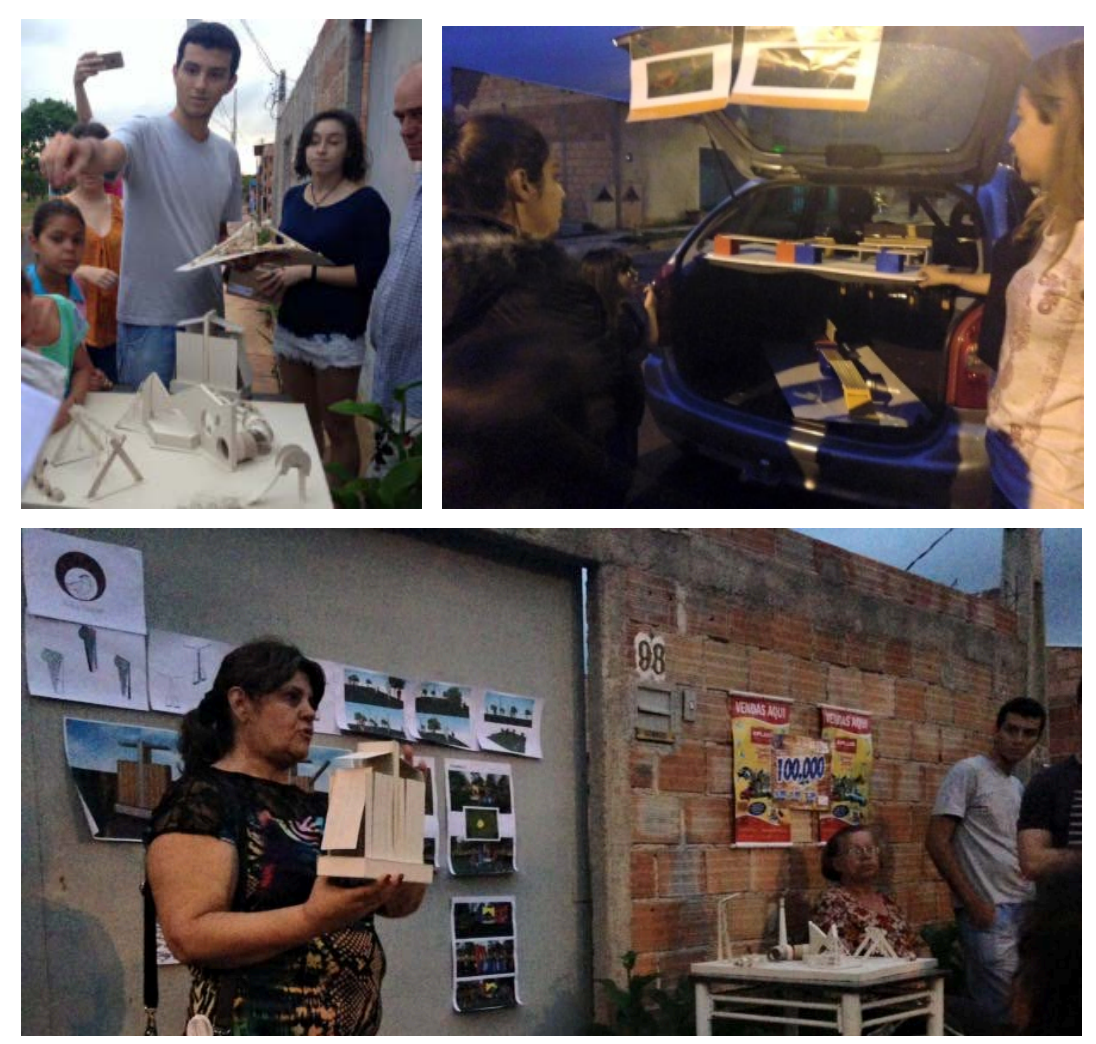

Figura 6 - Apresentação de Propostas de Projeto de Mobiliário

Fonte: Foto da segunda reunião dos alunos do curso de Design com a comunidade para apresentação das propostas de projeto de mobiliário da Praça Manaain.

\section{CONCLUSÃO}

As metodologias aqui apresentadas, sejam elas de design ou de arquitetura, lineares ou cíclicas, sempre consideram a presença do usuário, colaborando e interferindo no processo de projeto. Em via de regra podemos caracterizar essas metodologias aqui apresentadas pelo comprimento de algumas etapas semelhantes que consideram: definir o problema; coletar dados; criar propostas; avaliar propostas e implementar. Essas metodologias são escolhidas e utilizadas na prática profissional de designers e arquitetos sempre considerando um usuário real. Entretanto observa-se que no ensino, muitas vezes o usuário é simulado, o que limita sua presença em todas as etapas do trabalho durante o exercício em Ateliê. Nas análises dessas metodologias existentes, que também são adotadas para o ensino, chega-se à conclusão de que é importante em alguma etapa da formação acadêmica que o estudante possa experimentar e desenvolver projetos com a adoção de um usuário real para que possam compreender melhor os métodos existentes e estar melhor preparados para enfrentar o ofício de sua profissão.

Tendo como base o resultado do exercício de projeto aplicado na disciplina de Mobiliário 2 pode-se afirmar que a presença de um usuário real e não de um personagem, contribuiu com feedbacks em várias etapas do processo de projeto, interferindo na sua linearidade, o que não se faz possível quando se utilizam usuários fictícios.

Esta dinâmica possibilita ressaltar, o sentimento de identidade que se constrói nos usuários, quando estes participam de maneira colaborativa no processo de 
projeto, pois ajudaram a construir o espaço e ou mobiliário, gerando assim afetividade e consequentemente maior cuidado por parte destes com os objetos projetados e construídos. No caso da utilização de um usuário real por estudantes em exercícios de projeto, deve-se ater cuidado com a expectativa gerada nos usuários, pois o projeto em si, pode não vir a ser executado por razões diversas que não dependem dos estudantes que fazem parte da equipe de projeto.

\section{REFERÊNCIAS}

ARGAN G. C. Projeto e destino. São Paulo: Ática, 2001.

BAXTER, M. R. Projeto de Produto: Guia Prático para o Design de Novos Produtos. 2. Ed. São Paulo: Editora Blücher, 1998.

BONSIEPE, Gui. A tecnologia da tecnologia. São Paulo: Ed. Ed. Blucher, 1983

COELHO, Luiz Antônio L. Design método. Teresópolis: Novas Ideias, 2006.

GUIMARÃES, Ana L.S.V. Contextualização da Arte, da Técnica e da Tecnologia no Design Industrial: Um Estudo de Caso na Empresa Eletrolux /Curitiba-PR. Monografia. Programa de Pós Graduação CEFET- PR. 1997.

LÖBACH, Bernd. Design Industrial: Bases Para a Configuração dos Produtos Industriais. São Paulo: Edgard Blucher, 2001.

MUNARI, Bruno. Das coisas nascem coisas. São Paulo: Martins Fontes, 1998.

NEVES, André et al. XDM: Métodos Extensíveis de Design. In: CONGRESSO BRASILEIRO DE PESQUISA E DESENVOLVIMENTO EM DESIGN, 8., 2008, São Paulo. Anais... . São Paulo: AEND|BRASIL, 2008. p. 249 - 259. Disponível em: <https://pt.scribd.com/doc/58986048/XDM-Metodos-Extensiveis-de-Design>. Acesso em: 10 nov. 2015.

PAZMINO, Ana Verônica. Como se cria: 40 métodos para design de produto. São Paulo: Blucher, 2015.

PEREIRA, Juliano Aparecido. Desenho Industrial e Arquitetura no Ensino da FAU USP (1948-1968). 2009. 436 f. Tese (Doutorado) - Curso de Arquitetura e Urbanismo, Escola de Engenharia de São Carlos, Universidade de São Paulo, São Carlos, 2009.

SCHÖN, Donald A.. Educando o Profissional Reflexivo: um novo design para o ensino e a aprendizagem. Porto Alegre: Artmed, 2000. 256 p.

SILVA, Regina Celia Barbosa da. Arquitetura e design: os conteúdos que acercam seus programas de ensino. 2009. 193 f. Dissertação (Mestrado) - Curso de Arquitetura e Urbanismo, Universidade São Judas Tadeu, São Paulo, 2009.

SNYDER, James C.; CATANESE, Anthony. Introdução à Arquitetura. Rio de Janeiro: Campus, 1984. 